\title{
Finite Element and Artificial Neural Network Analysis of Thin-Walled Steel Perforated Sections in Compression
}

\author{
Meng $\mathrm{Wu}^{1,3}$, Zhijun $\mathrm{Lyu}^{1,3, *}$, Qian Xiang ${ }^{1,3}$, Yiming Song ${ }^{1,3}$ and Hongliang $\mathrm{Li}^{2,3}$ \\ ${ }^{1}$ College of Mechanical Engineering, Donghua University, Shanghai 201620, China \\ ${ }^{2}$ Shanghai Jingxing Storage Equipment Engineering Co., Ltd. Shanghai 201620, China \\ ${ }^{3}$ Shanghai Engineering Research Center of Storage \& Logistics Equipment \\ *Corresponding author
}

\begin{abstract}
The analysis of perforated members is a 3D problem in nature, therefore the traditional analytical expressions for the ultimate load of thin-walled steel sections can't be used for the perforated steel member design. In this study finite element method (FEM) and artificial neural network (ANN) were used to simulate the process of stub column tests based on specific codes. Results show that compared with those of the FEM model, the ultimate load predictions obtained from ANN technique were much closer to those obtained from the physical experiments. The ANN model for the solving the hard problem of complex steel perforated sections is very promising.
\end{abstract}

Keywords-artificial neural network (ANN); finite element method (FEM); steel perforated sections; ultimate load

\section{INTRODUCTION}

Pallet rack upright systems are usually made of thin-walled cold-formed steel sections that contain arrays of holes along the longitudinal axis of the member (Figure I). These perforations allow for hook-in end connectors to be used in order to obtain the so called hook-in beam-to-column connections that allows for easy height adjustability and ensure quick and efficient assembly. Despite their lightness, these structural systems are able to carry very high loads and can also raise considerable height. Usually, upright members are of mono-symmetrical sections, subjected to axial compression and bending about both axes. Nowadays, the ultimate load calculations on thinwalled column can be performed by means of specific computer programs: Thin-Wall[1] and CUFSM [2], based on the finite strip method(FSM); and GBTUL [3], based on the generalized beam theory(GBT). The finite element method can also be applied, but the computational cost is significantly higher. The use of these specific programs has made the direct strength method very quick and effective. At the moment, however, they cannot be applied to perforated members, since FSM and GBT are essentially 2D theories and the analysis of perforated members is a $3 \mathrm{D}$ problem. So, even if in the last years numerous investigations were devoted to the effects of holes and members' slenderness on the ultimate capacity of pallet rack uprights, no analytical method for the design of rack structures is generally accepted [4]. For this reason, the design of these structures is mostly based on experimental tests prescribed by specific codes. The increasing security demands from the storage racks make clear the need to explore novel ways of prediction on design load of thin-walled steel perforated sections furthermore.

This paper describes work that aims to use artificial neural network (ANN) technology to overcome many of the difficulties associated with the design load of thin-walled steel perforated sections. Results have been compared with those of the traditional finite element method. The relative experiments and research method are presented in detail.

\section{STub Column TeSTs}

The stub column tests were performed in order to observe the influence of perforations and the effects of local buckling on the ultimate strength of these members. They were carried out in accordance to AnnexA.2.1.2 (Alternative1) of EN15512[5]. The length of specimens was taken to respect the code requirements, i.e.: (1) the length of specimen shall be three times the greatest flat width of the section (ignoring intermediate stiffeners); (2) it shall include at least five pitches of the perforations, at the midway between two sets of perforations. The base and cap plates shall be bolted or welded to each end of the stub upright. The end-devices, at both ends, consist of pressure pads $30 \mathrm{~mm}$ thick with an indentation of $5 \mathrm{~mm}$ and a ball bearing of $40 \mathrm{~mm}$ diameter. Details of the testing set-up and supporting system are presented in Figure II. In order to build an ANN-based predictive model on thinwalled steel perforated sections, a total of ninety different data from stub columns compression experiments were collected from the shanghai Jingxing Logistic Equipment Engineering co., Ltd.

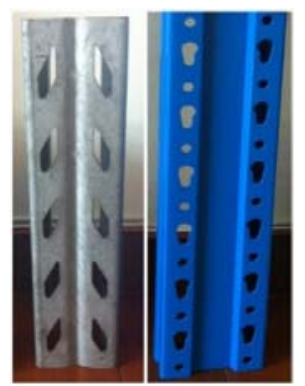

FIGURE I. ARRAYS OF PERFORATIONS OF COLUMNS 


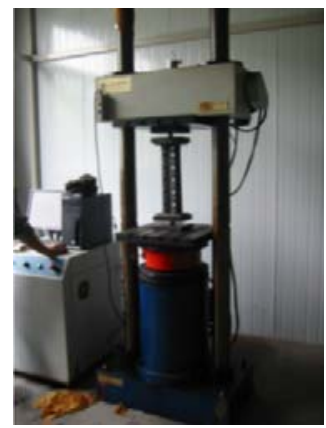

FIGURE II. THE TESTING SET-UP AND SUPPORTING SYSTEM

\section{ANN Model DESIGN}

The use of ANNs has grown in popularity during the last few years. The reason for this is that neural networks represent a novel and modern approach that can provide solutions in problems for which conventional mathematics, algorithms and methodologies are unable to find a satisfactory and acceptable solution [6]. These problems are usually very complex and some of the mechanisms involved have not been fully understood by the researchers dealing with them. Considering some salient features of ANN, there was proposed ANN-based ultimate load prediction system on thin-walled steel perforated sections. The internal detailed architecture of ANN is shown in Figure III. In intelligent model there were 9 input neurons such as perforated sections parameters and 1 output neuron, ultimate load, all listed in Table I. All the data are normalized, and it is pre-processed to be converted in the range $(-1,1)$ before being fed into ANN. The feed-forward neural network architecture is fully connected, that is, each neuron in the hidden layer is connected to all the neurons in the previous and next layer. Each neuron constitutes a learning unit. The neural network was trained for a different combination of hidden layer neurons and nine were found to be most suitable for this specific data set. The training function, "trainlm", had been transferred from the Matlab ANN toolbox to realize the training of these models. The transformation function of hidden neuron was "tansig" and "purelin" was the output layer function, which were also obtained from the ANN toolbox of the Matlab software. The learning rate $\eta$ was set from 0.01 to 0.07 , which can speed up the convergence of training function on the condition of accepted training precision.

\section{FINITE ELEMENT MODEL}

The finite element method has proven to be a very effective and powerful tool for analysis of perforated members and predicting their strength and behavior. Referring to AnnexA.2.1.2 of EN15512, a parametric finite element model has been created with the ANSYS code [7]. Element type SHELL 181 was selected to be used for the experiment simulations. This kind of four-node shell with six degrees of freedom per node lies in the linear and non-linear analysis, including large displacements and plasticity and rotations. The element type SOLID45 was also carefully applied for the load plates modelling. The eight-node solid three-dimensional element with three degrees of freedom per node is also frequently used for linear and nonlinear analysis. In our model, all slots and holes have been exactly reproduced. On a central node of the outer face of both load plates, the displacements are properly appointed, i.e. the line defined by these two nodes is the load line. The all node displacements of the bottom plate and the transversal displacements of the node at the top plate have been set up to zero. The axial displacement of the load line is gradually increased step by step until the stub can be no longer in force. The displacement controlled method has been used to simulate an applied load on the top end of the stub column. The displacement is added in continuous increments until it obviously begins to decrease or remains unchanged for an extraordinary lapse of displacement. At that moment, the maximum load in the stub can be considered the failure force i.e. so-called ultimate load.

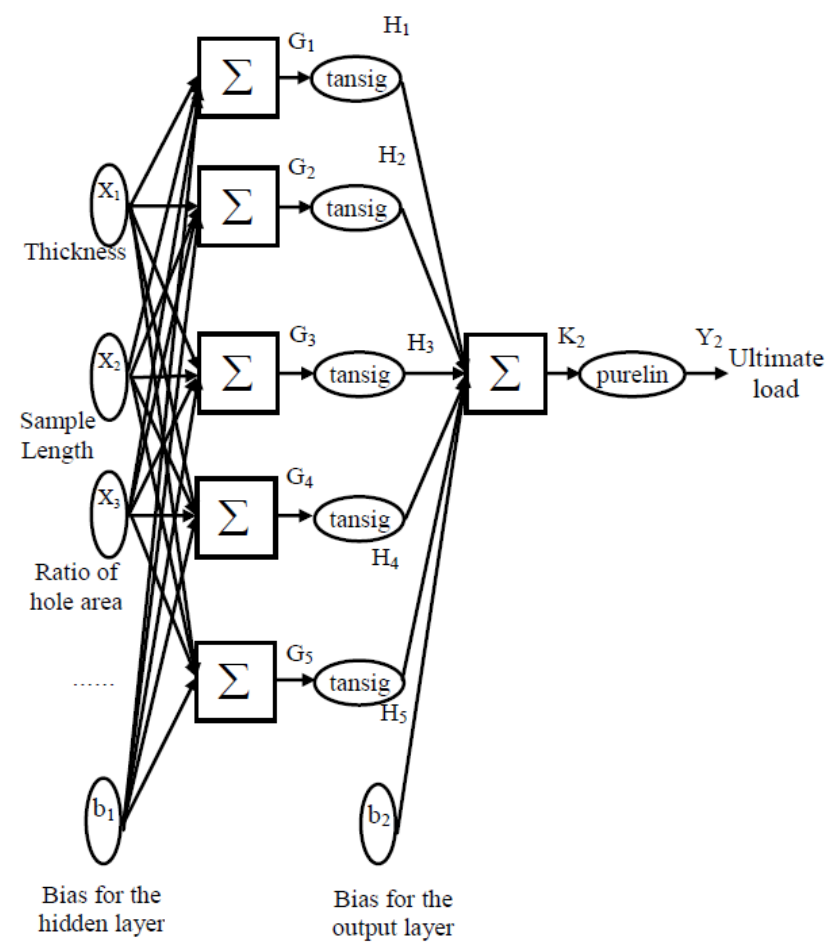

FIGURE III. ARTIFICIAL NEURAL NETWORK ARCHITECTURE
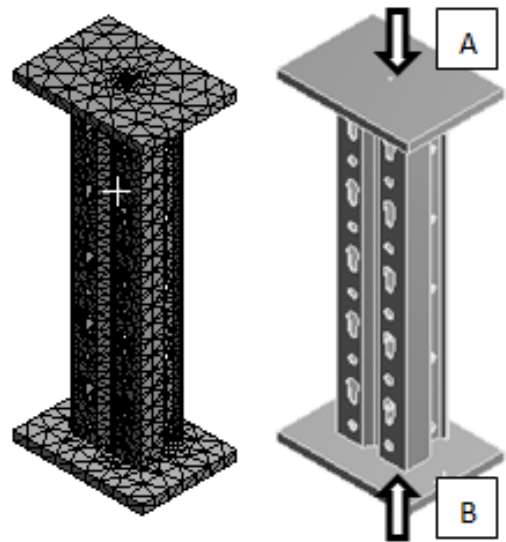

FIGURE IV. MESH, CONSTRAINT AND LOADS ETTING OF SIMULATION MODEL 
TABLE I. RELATIONAL MAPPING BETWEEN INPUT AND OUTPUT PARAMETERS

\begin{tabular}{|c|c|c|c|c|c|c|c|c|c|c|}
\hline \multirow{2}{*}{$\begin{array}{c}\text { Column } \\
\text { type }\end{array}$} & \multicolumn{9}{|c|}{ Input index } & \multirow{2}{*}{\begin{tabular}{|c|}
$\begin{array}{c}\text { Output } \\
\text { index }\end{array}$ \\
$\begin{array}{c}\text { Ultimate } \\
\text { load }(N)\end{array}$ \\
\end{tabular}} \\
\hline & $\begin{array}{c}\text { Web } \\
\text { Width } \\
(\mathrm{mm})\end{array}$ & $\begin{array}{c}\text { Thickness } \\
\text { (mm) }\end{array}$ & $\begin{array}{c}\text { Flange } \\
\text { width } \\
(\mathrm{mm})\end{array}$ & $\begin{array}{c}\text { Opening } \\
\text { Size } \\
(\mathrm{mm}) \\
\end{array}$ & $\begin{array}{c}\text { Sample } \\
\text { Length } \\
(\mathrm{mm})\end{array}$ & $\begin{array}{c}\begin{array}{c}\text { Ratio of } \\
\text { hole } \\
\text { area (\%) }\end{array} \\
\end{array}$ & $\begin{array}{l}\text { Number } \\
\text { of bends }\end{array}$ & $\begin{array}{c}\text { Number } \\
\text { of right } \\
\text { angles }\end{array}$ & $\begin{array}{l}\text { Number of } \\
\text { reinforcement }\end{array}$ & \\
\hline M60 & 60 & 1.8 & 55 & 34 & 350 & 14.951 & 8 & 4 & 0 & 80309.17 \\
\hline M75 & 75 & 1.8 & 58 & 45 & 400 & 12.190 & 12 & 4 & 1 & 122051.82 \\
\hline M90A & 90 & 2 & 65 & 50 & 400 & 11.287 & 12 & 4 & 1 & 137228.18 \\
\hline M100B & 100 & 2.5 & 90 & 52 & 400 & 10.667 & 20 & 4 & 3 & 205633.26 \\
\hline $\mathrm{M} 120 \mathrm{~A}$ & 120 & 3 & 95 & 76 & 500 & 8.889 & 12 & 4 & 1 & 269336.45 \\
\hline
\end{tabular}

TABLE II. COMPARISON AMONG THE MEASUREDVALUES, PREDICTED VALUES AND FINITE ELEMENT NUMERICAL VALUES

\begin{tabular}{|c|c|c|c|c|c|}
\hline Column type & Measure (N) & Predict (N) & Absolute error (\%) & $F E M(N)$ & Absolute error (\%) \\
\hline M45-1.5 & 48385.6 & 48429.2 & 0.09 & 49856.3 & 3.04 \\
\hline M60-2 & 107142.8 & 104077.6 & 2.86 & 116348.7 & 8.59 \\
\hline M75-1.8 & 120057 & 115392.3 & 3.89 & 130147.5 & 8.41 \\
\hline M90A-2 & 136364.2 & 140316.6 & 2.90 & 144199.2 & 5.73 \\
\hline M100B-2 & 159740 & 162860.8 & 1.95 & 167594.5 & 4.92 \\
\hline M120A-3 & 268689.3 & 271741.8 & 1.14 & 283439.5 & 5.49 \\
\hline M120B-3.5 & 413894 & 417135.6 & 0.78 & 449071.2 & 8.50 \\
\hline \multicolumn{6}{|c|}{$\ldots$} \\
\hline \multicolumn{2}{|c|}{ Mean absolute error (\%) } & \multicolumn{3}{|c|}{1.85} & 6.05 \\
\hline \multicolumn{2}{|c|}{ Correlation coefficient. $R$} & \multicolumn{3}{|c|}{0.99} & 0.97 \\
\hline \multicolumn{2}{|c|}{ Cases with over $5 \%$ error } & \multicolumn{3}{|c|}{2} & 13 \\
\hline
\end{tabular}

\section{RESULT AND DisCUSSION}

Within the total of 90 data sets from stub columns tests, the first 70 data sets are used for network training, and the others are set aside to evaluate the trained network's performance (prediction). Network training is terminated based on the accepted prediction accuracy of these models such as for the corresponding deviation not more than $5 \%$ between the expected values and the real values. After the completion of model development or training, the other 20 data sets are input to the intelligent model to verify the accuracy of model generalization. The results are shown in Table II, where "Measure", "Predict" and "FEM" refer to the measured values, the predicted values and finite element numerical values, respectively. Statistical parameters such as the correlation coefficient $\mathrm{R}$ between the expected and real value, and mean absolute error $\%$ are used to judge the predictive power of the
ANN models. It is evident that the accuracy of the predictive models is relatively high in all ( $\mathrm{R}>95 \%$ ), while ANN model in the mean absolute error and the ratio of the cases with more than $5 \%$ error is lower than FEM model. So the ANN models can be more suitable to assist the security estimation during the steel member design.

\section{CONCLUSION}

Due to computational accuracy and complexity, the analytical expressions for the ultimate load of thin-walled steel perforated sections are not used for steel member design so far. In this paper, the load predictions from the neural network were compared with those obtained from the FE model. It was found that the load predictions obtained from ANN technique were much closer to those obtained from the physical experiments. We demonstrate that, trained with the data sets from engineering experiment, the ANN model is able to predict the 
design load of different columns through continually selflearning, which can help the engineer to make the better design decision. Although the results of our work seem to be very preliminary, we have observed that the simulation model for the solving the hard problem of complex design optimization is promising. With advancement of service science, data mining and cloud computing techniques, one looks forward to the era in which much of the engineer's subject intuition in constructional steel industry will finally be replaced by more smart and friendly expert systems.

\section{ACKNOWLEDGMENT}

This work was financially supported by Shanghai Municipal Natural Science Foundation (15ZR1400600) and technology innovation program of Shanghai Municipal Science and Technology Commission (15DZ0500400 and 17DZ2283800).

\section{REFERENCES}

[1] Papangelis JP, Hancock GJ., Computer analysis of thin-walled structural members, Computers \& Structures 1995;56:157-76.

[2] Schafer BW, Adany S., Buckling analysis of cold-formed steel members using CUFSM: conventional and constrained finite strip methods. In: Proceedings of the eighteenth international specialty conference on coldformed steel structures. Orlando, FL; October 2006.

[3] Bebiano R, Pina P, Silvestre N, Camotim D., GBTUL_buckling and vibration analysis of thin-walled members. DECivil/IST. Technical University of Lisbon;2008. </http://www.civil.ist.utl.pt/gbt)>.

[4] S.N.R. Shah, N.H. RamliSulong, M.Z. Jumaat, et al. State of theart review on the design and performance of steel pallet rack connections. Engineering Failure Analysis. 2016 (66).p.240-258.

[5] European Standard EN 15512:2009, Steel static storage systemsadjustable pallet racking systems-principles for structural design. Brussels: European Committee for standardization; 2009.

[6] Alberto Prieto n, Beatriz Prieto, Eva Martinez Ortigosa, et al, Neural networks: an overview of early research, current frameworks and new challenges, Neuro computing, 214(2016), 242-268.

[7] ANSYS, Inc. Ansys Documentation. 